\section{俩 Heighten Science \\ P U B L I C I T I O N S Corporation ISSN 2575-0143}

\title{
Are S-Klotho's Maximal concentrations dependent on Exercise Intensity and Time in young adult males?
}

\author{
Moran Sciamama Saghiv ${ }^{*}$, David Ben-Sira², Ehud Goldhammer ${ }^{3}$ \\ and Michael Sagiv ${ }^{2}$ \\ ${ }^{1}$ Department of Kinesiology, College of Health \& Human Sciences, NC A\&T State University, USA \\ ${ }^{2}$ Life Sciences Department, Wingate College, Wingate, Israel \\ ${ }^{3}$ Heart Institute Bnai-Zion Haifa Medical Center, Technion, Haifa, Israel
}

\begin{abstract}
*Address for Correspondence: Moran SciamamaSaghiv, PhD, Associate Professor of Clinical Exercise Physiology, Chair, Department of Human Performance and Leisure Studies, College of Health and Human Sciences, NC A\&T State University, Corbett HPER Center, Suite 215, Room 216, 1601 East Market Street/John Mitchell Drive Greensboro, North Carolina 27411, USA, Tel: 336.285.3560; Email: moransaghiv@gmail.com

Submitted: 20 February 2019

Approved: 07 March 2019

Published: 08 March 2019
\end{abstract}

Copyright: () 2019 Saghiv MS, et al. This is an open access article distributed under the Creative Commons Attribution License, which permits unrestricted use, distribution, and reproduction in any medium, provided the original work is properly cited

Keywords: Anti-aging; Aerobic training; Untrained individuals; Maximal oxygen uptake; ELISA kit; ROS; Nitric acid

Check for updates

\section{Abstract}

The purpose of the present study was to define the period of time in which aerobic training does not increase further serum S-Klotho levels in untrained young adult males, and to examine the relation between plasma S-Klotho concentration and maximal oxygen uptake $\left(\mathrm{VO}_{2 \max }\right)$.

Methods: Sixty (60) untrained subjects $(27.05 \pm 1.1$ years) were divided into 2 groups, both exercised six months $4 \times \mathrm{wk}^{-1}$ for the duration of $45 \mathrm{~min} \times$ session. One group (LTI) exercised below the anaerobic threshold at $40-50 \%$ of $\mathrm{VO}_{2 \max }$, while the second group $(\mathrm{HTI})$ worked above the anaerobic threshold at $65-70 \%$ of $\mathrm{VO}_{2 \max }$. Testing sessions were performed at $0,2,4$, and 6 months. Blood samples were drawn after overnight fasting; S-Klotho was analyzed using an ELISA kit.

Results: Following 2 and 4 months, significant $(p \leq 0.05)$ increases were noted in the HTI group, at the fourth testing session, S-Klotho leveled off. In the LTI group, S-Klotho remained almost unchanged. Findings of the present study, support emerging evidence suggesting that a relation between plasma S-Klotho concentration and VO2max exists.

Conclusions: Data suggest that increases in S-Klotho is tidally associated with $\mathrm{VO}_{2 \max }$ levels. In addition, the S-Klotho increase levels-off following 4 months of aerobic training. Exercising below the anaerobic threshold does not increase $\mathrm{VO}_{2 \max }$ and thus, does not increase S-Klotho.

\section{Introduction}

The $\alpha$-Klotho protein circulates in the blood as Soluble-Klotho (s-Klotho), which in humans, decreases in the serum with aging [1]. S-Klotho in humans is a pleiotropic protein with a considerable influence on longevity [2]. Exercise is a very active approach averting leading reasons of disease and as relates to aging. Exercise and Klotho gene expression reduce the risk of cardiovascular events in patients with prior coronary artery disease (CAD), thus, aerobic exercise may decrease the risk of mortality $[3,4]$. However, an association between low levels of s-Klotho and the occurrence and severity of cardiovascular disease have been reported, as well as a reduction of cardiovascular risk when levels were high [5]. Untrained, physically inactive individuals present low blood s-Klotho levels [6]. Recent studies [6,7] suggested that aerobic exercise training, is associated with increase blood s-Klotho and maximal oxygen uptake $\left(\mathrm{VO}_{2}\right)$ values. Therefore, the purpose of the present study was to assess the influence of time and intensity (below or above the anaerobic threshold) on s-Klotho serum levels in untrained individuals.

\section{Methods}

\section{Subjects}

Sixty (60) young $(27.05 \pm 1.1$ years), healthy, untrained, and male subjects, were 
divided randomly into two even groups. All subjects were evaluated as of "poor" fitness according to aerobic capacity and age.

\section{Pre-testing procedures}

Approval for the study was achieved in accordance with the Helsinki declaration, approved by the Clinical Science Center Committee on Human Subjects. A written informed consent was obtained from each subject, a health history questionnaire was filled, and risk stratification followed.

Subjects judged free of coronary artery disease by clinical history, and the absence of major risk factors were included in the study.

\section{Procedures}

Subjects were seated for five minutes before having their resting values obtained, had their resting values obtained, then proceeded to undergo a maximal exercise stress test. Height, weight, heart rate, blood pressure, and s-Klotho values were obtained at rest. Subjects with no counter indications for exercise due to the stress test continued as subjects in the study. None of the subjects had exercise counter indications.

Both groups exercised six months, $4 \times \mathrm{wk}^{-1}$ for the duration of $45 \mathrm{~min} \times$ session ${ }^{-1}$. The first group exercised below the anaerobic threshold (Low Training Intensity; LTI) at $40-50 \% \mathrm{VO}_{2 \max }$, while the second group (High training Intensity; HTI) worked above the anaerobic threshold at $65-70 \%$ of $\mathrm{VO}_{2 \max }$. Testing sessions were performed at 0,2 , 4 and 6 months.

Adipose fat assessment included measurement of total body weight $( \pm 0.05 \mathrm{~kg})$, skin fold thicknesses at 8 sites $( \pm 1 \mathrm{~mm}$ ) using the Lange Caliper (chest, axilla, triceps, sub-scapula, abdomen, suprailium, front thigh and circumferences at the shoulder). Anthropometric procedures followed the recommendations of Behnke and Wilmore [8].

Following warm-up, subjects underwent a graded maximal treadmill test utilizing the standard Bruce Protocol [9]. Maximal tests were terminated by the following criteria: a) leveling off or no further increase in $\mathrm{VO}_{2}$ with increasing work rate, b) attainment of the age predicted maximum heart rate, c) respiratory exchange ratio > 1.1 , and d) when the subject could not keep up with the load, according to the guidelines of the American College of Sports Medicine [10]. $\mathrm{VO}_{2}$ was determined breath by breath utilizing the Medical Graphics (St. Paul, MN) metabolic cart. The metabolic cart was calibrated before each test with known primary standard quality gases. Heart rate and electrocardiogram were monitored continuously, using a Burdick Eclipse 400 3-channel, 12-lead ECG recorder system, and oscilloscope. Five-second recordings were obtained at rest and at peak exercise. Blood pressure was taken using a standard sphygmomanometer cuff and mercury manometer mounted at eye level, at rest and at peak exercise.

\section{Blood sampling and procedures}

Peripheral venous blood samples $(2.5 \mathrm{~mL})$ were collected by sterile antecubital venipuncture techniques into ethylenediam-inotetraacetate containing tubes. Time of day for blood sampling was kept consistent to control for problems associated with diurnal variation. Blood collection was obtained from each subject once for each visit.

\section{Analysis}

Blood samples were drawn from a forearm vein after overnight fasting, centrifuged for 15 minutes at $2700 \mathrm{rpm}$, separated and frozen at $-70^{\circ} \mathrm{C}$ until use. Klotho levels in the serum were analyzed using an $\alpha$-klotho Enzyme Linked Immunosorbent Assay ELISA kit (Immuno-Biological Laboratories Co, Japan). The kit has been validated and widely used for the measurement of klotho levels [11-13]. Measurements were conducted 
according to the manufacturer instructions. The intra- and inter-assay coefficients of variation ranged from 2.7 to $9.8 \%$.

\section{Statistical methods}

Data are reported as mean \pm SD values. Physiological responses at rest and maximal exercise between the two groups were statistically assessed by a one-way ANOVA with repeated measure on the exercise-rest main effect. Post hoc analysis was performed by using the Tukey 2 multiple comparison tests. Comparisons between the groups for $\mathrm{s}$-Klotho levels were based on t-tests for unpaired samples. The level of significance was set at $\alpha \leq 0.05$.

\section{Results}

All subjects completed the exercise challenge without difficulties or abnormal symptoms. Mean descriptive data for the two experimental groups are presented in tables 1,2. Figure 1 discloses that s-Klotho 0 in the HTI group, increased significantly $(\mathrm{p} \leq 0.05)$ from baseline to 2 months, and from 2 months to 4 months, yet insignificantly increased thereafter. The LTI group as a control did not significantly differ in their values from pretesting values to the end of the study; namely the $6^{\text {th }}$ month. Figure 2 , reveals that $\mathrm{VO}_{2}$ in the HTI group, increased significantly $(\mathrm{p} \leq 0.05)$ and gradually following the $2^{\text {nd }}$ and $4^{\text {th }}$ training months without significant differences from the $4^{\text {th }}$ month to the $6^{\text {th }}$. The LTI group as a control did not significantly ( $\left.p>0.05\right)$ differ in their $\mathrm{VO}_{2}$ values from pretesting to the end of the study; namely the $6^{\text {th }}$ month.

\begin{tabular}{|c|c|c|}
\hline Table 1: Subjects' Physical Characteristics at Rest. (mean \pm S.D). & HTI \\
\hline Variables & LTI & 30 \\
\hline N of subjects & 30 & $27.2 \pm 1.1$ \\
\hline Age (years) & $26.9 \pm 1.1$ & $70.1 \pm 1.8$ \\
\hline Weight $(\mathrm{kg})$ & $71.3 \pm 1.7$ & $179.8 \pm 2.1$ \\
\hline Height (cm) & $180.4 \pm 2.0$ & $12.4 \pm 1.7$ \\
\hline Fat (\%) & $12.1 \pm 1.6$ & $3.4 \pm 0.3$ \\
\hline
\end{tabular}

Table 2: Physiological Responses at Rest and Pre-Post Training at Maximal Exercise in Both Groups (mean S.D).

\begin{tabular}{|c|c|c|c|c|}
\hline Variables & HTI & HTI & LTI & LTI \\
\hline & Rest & Exercise & Rest & Exercise \\
\hline $\begin{array}{l}\text { Lactic acid } \\
\left(\mathrm{mmol} \cdot \mathrm{L}^{-1}\right)\end{array}$ & $1.3 \pm 0.3$ & $12.8 \pm 1.2$ & $1.4 \pm 0.3$ & $12.1 \pm 1.1$ \\
\hline $\begin{array}{l}\text { Heart Rate } \\
\text { (beats } \mathrm{min}^{-1} \text { ) }\end{array}$ & $67.1 \pm 9.3$ & $198 \pm 7.2$ & $79.6 \pm 8.4 \mathrm{a}$ & $194.4 \pm 8.2$ \\
\hline $\begin{array}{c}\text { Systolic BP } \\
(\mathrm{mmHg})\end{array}$ & $109.2 \pm 6.8$ & $180.4 \pm 7.6$ & $110 \pm 8.0$ & $182 \pm 6.4$ \\
\hline $\begin{array}{l}\text { Diastolic BP } \\
(\mathrm{mmHg})\end{array}$ & $70.6 \pm 2.7$ & $68.0 \pm 2.2$ & $72.2 \pm 3.3$ & $71.0 \pm 2.4$ \\
\hline
\end{tabular}

$\mathrm{HTI}=$ Exercising group; $\mathrm{LTI}=$ Inactive group; $\mathrm{a}=$ significant $(\mathrm{p}>0.05)$ differences between both groups.

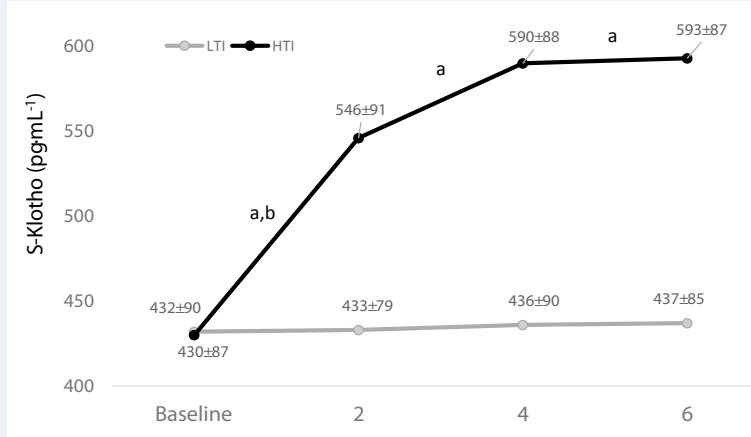

Figure 1: S-Klotho levels in HTI and LTI (mean $\pm S D) ; a .=$ Significant differences between HTI and LTI $(p>0.05) ; b=$ Significant difference between months of training. 


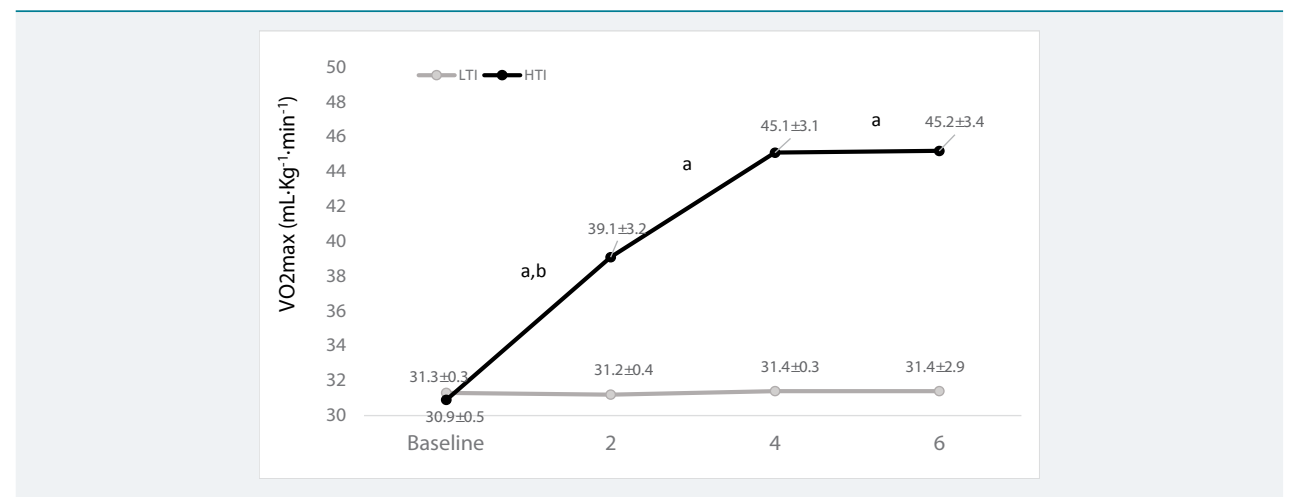

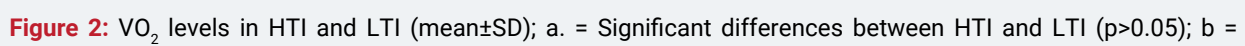
Significant difference between months of training.

\section{Discussion}

This study demonstrated that aerobic exercise training induced a significant increase in plasma s-Klotho concentration following six months of aerobic training. Additionally, it revealed that following four months of aerobic training S-Klotho values leveled off. In the LTI group no significant changes in s-Klotho and $\mathrm{VO}_{2 \max }$ were found. aS-Klotho was increased in the HTI group, suggesting that circulating s-Klotho levels were increased in response to long-lasting aerobic exercise training, and that the response depends on the subjects' fitness level, since s-Klotho increased in a similar pattern as $\mathrm{VO}_{2 \max }$. Maximal oxygen uptake ( $\left(\mathrm{Vo}_{2 \max }\right.$ ), is largely used as the best single physiological variable to evaluate the cardiopulmonary function ability. Furthermore, the noninvasively breath-by-breath method to determine the value of exercise training effectiveness in health and disease by measuring $\mathrm{Vo}_{2 \max }$ is powerful tool for investigational and clinical evaluations. However, the mechanism by which $\mathrm{Vo}_{2}$ level influence blood s-Klotho values is yet unclear.

Previously it has been reported that oxidizing free radical species (ORS) are generated during aerobic bouts [13]. Skeletal muscles generate Super Oxide and Nitric Oxide which is increased by muscle contraction activity [14]. ROS is essential for skeletal muscle force generation, however, ROS in high values may reduce muscle contraction properties and thus, result in early exhaustion $[15,16]$. The increase in $\mathrm{s}$-Klotho following aerobic exercise training may be a response to ROS that increase in muscle cells as a result of aerobic training.

Although the association between s-Klotho and aerobic exercise training is not clear, s-Klotho reduces programmed cell death (apoptosis) through Nitric Oxide production and thus, ? ? was also observed in response to an acute exercise in young and old mice, suggesting that this may be a good model for mechanistically probing the role of aerobic exercise on Klotho expression [18]. Endurance exercise such as running, cycling and swimming appear to benefit and minimize the physiological alterations that occur during aging and may contribute to improvements in health and well-being [19]. Previously it has been suggested that aerobic training above the anaerobic threshold intensities increase $\mathrm{VO}_{2 \max }$ [20]. The unchanged $\mathrm{VO}_{2 \max }$ in the LTI group and s-Klotho, is probably due to the low training intensity; namely below the anaerobic threshold and below of heart rate reserve [21]. Prolonged or high-intensity exercise result in oxidative damage to macromolecules in both blood and skeletal muscles. However, low intensity aerobic training does not produce ROS thus, S-Klotho levels did not increase in the LTI group, since s-Klotho protein suppresses oxidative stress [17,22].

\section{Study's limitations}

There are limitations in the present study that should be well-thought-out when 
understanding the results. a) Only s-Klotho in the plasma was measure and, b) mechanisms causal of the effects of aerobic exercise on Klotho were not investigated in this study.

In conclusion, data suggest that increases in s-Klotho is close associated with $\mathrm{VO}_{2 \max }$ levels. In addition, the s-Klotho increase levels-off following 4 months of aerobic training. Exercising below the anaerobic threshold does not increase $\mathrm{VO}_{2 \max }$ and thus, does not increase s-Klotho.

\section{References}

1. Maekawa $\mathrm{Y}$, Ohishi M, Ikushima M, Yamamoto K, Yasuda O, et al. Klotho Protein Diminishes Endothelial Apoptosis and Senescence via a Mitogen-Activated Kinase Pathway. Geriatr Gerontol Int. 2011; 11: 510-516. Ref.: https://goo.gl/T2kFua

2. Kim JH, Hwang KH, Park KS, Kong ID, Cha SK. Biological Role of Anti-Aging Protein Klotho. J. Lifestyle Med. 2015; 5: 1-6. Ref.: https://goo.gl/3ywkYX

3. Navarro-González JF, Donate-Correa J, Muros de Fuentes M, Pérez-Hernández H, Martínez-Sanz R, et al. Reduced Klotho is Associated with the Presence and Severity of Coronary Artery Disease. 2014; Heart. 2014; 100: 34-40. Ref.: https://goo.gl/8mRBnH

4. Kingsley D. Aging and Health Care Costs: Narrative versus Reality. Poverty \& Public Policy. 2015; 7:3-21. Ref.: https://goo.gl/uZHt4t

5. Martín-Núñez E, Donate-Correa J, Muros-de-Fuentes M, Mora-Fernández C, Navarro-González JF. Implications of Klotho in Vascular Health and Disease. World J Cardiol. 2014; 6: 1262-1269. Ref.: https://goo.gl/8ruuoV

6. Saghiv MS, Sira DB, Goldhammer E, Sagiv M. The Effects of Aerobic and Anaerobic Exercises on Circulating Soluble-Klotho and IGF-I in Young and Elderly Adults and in CAD Patients. J Circ Biomark. 2017; 6:1849454417733388. Ref.: https://goo.gl/VKkH6z

7. Saghiv M. Effects of Aerobic Exercise Training on S-Klotho in Young and Elderly. JJ Physiology. 2015; 1: 001. Ref.: https://goo.gl/8W69JV

8. Behenke AR, Wilmore J. Evaluation and regulation of Body Build and Composition. Englewood Cliffs, N.J. Prentile Hall, Inc. 1974;

9. American College of Sports Medicine. ACSM's Guidelines for Exercise Testing and Prescription $10^{\text {th }}$ edition, Philadelphia, PA: Lippincott Williams \& Wilkins; 2014; 145-147 and 165-199. Ref.: https://goo.gl/ZVQKaC

10. Yamazaki Y, Imura A, Urakawa I, Shimada T, Murakami J, et al. Establishment of Sandwich ELISA for Soluble Alpha-Klotho Measurement: Age-Dependent Change of Soluble Alpha-Klotho Levels in Healthy Subjects. Biochem Biophys Res Commun 2010; 398: 513-518. Ref.: https://goo.gl/81XzNR

11. Pedersen L, Pedersen SM, Brasen CL, Rasmussen LM. Soluble Serum Klotho Levels in Healthy Subjects. Comparison of Two Different Immunoassays. Clin Biochem 2013; 46:1079-1083. Ref.: https://goo.gl/yjgXPg

12. Heijboer AC, Blankenstein MA, Hoenderop J, de Borst MH, Vervloet MG, et al. Laboratory Aspects of Circulating Alpha-Klotho. Nephrol Dial Transplan. 2013; 28: 2283-2287. Ref.: https://goo.gl/RymBJD

13. McArdle A, Pattwell D, Vasilaki A, Griffiths RD, Jackson MJ. Contractile Activity-Induced Oxidative Stress: Cellular Origin and Adaptive Responses. Am J Physiol Cell Physiol. 2001; 280: C621-627. Ref.: https://goo.gl/rHtB8f

14. McArdle A, Pollock N, Staunton CA, Jackson MJ. Aberrant Redox Signalling and Stress Response in Age-Related Muscle Decline: Role in Inter and Intra-Cellular Signalling. Free Radic Biol Med. 2019; 132: 50-57. Ref.: https://goo.gl/7x7EuQ

15. Powers KS, Jackson JM. Exercise-Induced Oxidative Stress: Cellular Mechanisms and Impact on Muscle Force Production. Physiol Rev. 2008; 88: 1243-1276. Ref.: https://goo.gl/7UtBHB

16. Powers KS, Nelson WB, Hudson BM. Exercise-Induced Oxidative Stress in Humans: Cause and Consequences. Free Radical Biology and Medicine. 2011; 51: 942-950. Ref.: https://goo.gl/ruxq6D

17. Carracedo J, Buendía P, Merino A, Madueño JA, Peralbo E, et al. Klotho Modulates the Stress Response in Human Senescent Endothelial Cells. Mech Ageing Dev. 2012; 133: 647-654. Ref.: https://goo.gl/wnb5Sr 
18. Avin KG, Coen PM, Huang W, Stolz DB, Sowa GA, et al. Skeletal Muscle as a Regulator of the Longevity Protein, Klotho Front. Physiol. 2014; 5: 189. Ref.: https://goo.gl/oEawDv

19. American College of Sports Medicine, Chodzko-Zajko WJ, Proctor DN, Fiatarone Singh MA, Minson CT, et al. American College of Sports Medicine Position Stand. Exercise and Physical Activity for Older Adults. Med Sci Sports Exerc. 2009; 41: 1510-1530. Ref.: https://goo.gl/NcmTcx

20. Carter H, Jones AM, Doust JH. Effect of Six weeks of Endurance Training on the Lactate Minimum Speed. J Sports Sci. 1999; 17: 957-967. Ref.: https://goo.gl/hKSVXv

21. Weltman A. The Blood Lactate Response to Exercise. Champaign, IL: Human Kinetics. 1995; Ref.: https://goo.gl/RjXWat

22. Yamamoto M, Clark JD, Pastor JV, Gurnani P, Nandi A, et al. Regulation of Oxidative Stress by the Anti-aging Hormone Klotho. J Biol Chem. 2005; 280: 38029-38034. Ref.: https://goo.gl/h6tqix 